\title{
TONICIDAD DIFERENTE ENTRE PORTUGUÉS Y ESPAÑOL. PROCESOS DE ADECUACIÓN
}

\author{
STRESS DIFFERENCES BETWEEN SPANISH AND PORTUGUESE \\ Ignacio VázQuez DiéGueZ \\ Universidade da Beira Interior \\ jivd@ubi.pt
}

Fecha de recepción: $13-07-2017$

Fecha de aceptación: 11-10-2017

\section{RESUMEN}

En este artículo se dan ciertas informaciones para intentar explicar la diferente pronunciación de un conjunto de palabras entre español y portugués. Las causas de dicha diferencia son diversas. Se observa, sobre todo, una distinta evolución y/o adaptación del término originario (principalmente latín y griego), en ocasiones esperable y en otras no; también se ve la influencia de una tercera lengua (francés, sobre todo, inglés y otras) y en palabras formadas a partir de otras dos, a veces domina el acento de una y a veces el de la otra.

PALABRAS CLAVE: prosodia; portugués; español.

\section{ABSTRACT}

The aim of this article is to try and explain the different pronunciation of a set of words between Spanish and Portuguese. The causes of this difference are diverse. We observe, above all, a different evolution and/or adaptation of the original term (mainly Latin and Greek), sometimes expected and sometimes not; the influence of a foreign language (French, especially, English and others) is also seen, and -in compound words formed from other two - sometimes prevails the stress of one word and sometimes prevails the other.

KEY WORDS: prosody; Portuguese; Spanish. 


\section{PRESENTACIÓN}

Se pretende en estas líneas ofrecer un esquema comparativo de un conjunto de palabras con igual étimo que difieren en su tonicidad entre la lengua portuguesa y la española. Este estudio no quiere apenas ofrecer dichos vocablos en un listado, quiere aportar información dispersa para entender históricamente esa diferente adecuación. Es una ayuda para el profesor y para el alumno curioso. La diacronía ayuda a entender esos procesos. Léase lo que escribe Coloma Lleal al respecto:

Cuando en la enseñanza de español para extranjeros intentamos explicar algunos temas de nuestra gramática a partir de planteamientos rigurosamente sincrónicos, nos vemos a menudo obligados a recurrir a argumentos ad hoc, a inventarnos curiosas reglas plagadas de excepciones o, lo que a mi juicio es más grave, a falsear los datos en aras de una explicación aparentemente más clara. No se trata de atosigar innecesariamente a nuestros alumnos con unos métodos de análisis que no corresponden a sus necesidades comunicativas. Pero el profesor ha de conocer las líneas generales de la evolución para, a continuación, intentar encontrar la manera de exponer sucintamente el porqué de algunas aparentes anomalías. $(2008,151)$

Las palabras comentadas se han extraído del lemario del Diccionario bilingüe Esencial Português-Espanhol/Español-Portugués de Larousse (2010). La información etimológica referente al origen de la palabra se basa en el DRAE (Diccionario de la lengua española) — contrastada con el Dicionário Houaiss da língua portuguesa (HOUAISS)—, ampliada en muchos casos y siempre con la transcripción fonética. Cuando se tiene el dato, se ofrece la fecha de la primera documentación en cada lengua: para el portugués, el HOUAIss; para el español, el Corpus del Nuevo diccionario histórico [CDH] de la Real Academia Española. Se han utilizado diferentes materiales, sobre todo lexicográficos, para la consecución y realización del trabajo, todos ellos debidamente referenciados en la bibliografía.

\section{CONSIDERACIONES GENERALES SOBRE LA ACENTUACIÓN}

En latín clásico no había palabras agudas; las bisílabas eran siempre graves y las de más de dos sílabas se regían por la llamada «ley de las tres sílabas» que implicaba lo siguiente:

— si la penútima sílaba era libre y poseía vocal breve, la palabra era esdrújula $<$ xa/xă/ xa> (digitus ['digitus $\left.{ }^{1}\right]$ );

— si la penúltima sílaba era libre o trabada y poseía vocal larga, la palabra era llana por naturaleza, <xa/'xā(x)/xa> (generōsus [gene'ro:sus], trimēstris [tri'me:stris]) y

\footnotetext{
${ }^{1}$ Cabe decir que las vocales latinas largas eran pronunciadas cerradas y las breves abiertas. El ejemplo propuesto debería ser transcrito como dĭğtŭs ['dıgıtrs]. En este trabajo usaremos una transcripción simplificada, sin marcar la abertura vocálica en latín.
} 
— si la penúltima sílaba era trabada y poseía vocal breve, se consideraba sílaba larga por posición $<\mathrm{xa} / \mathbf{x a ̆ x} / \mathrm{xa}>$ (castěllum [kas'tzl:um] $>$ castēllum) ${ }^{2}$.

En griego antiguo podía haber palabras agudas, llanas y esdrújulas. Palabras de más de dos sílabas, aunque la penúltima fuese larga, podían ser esdrújulas siempre que la última

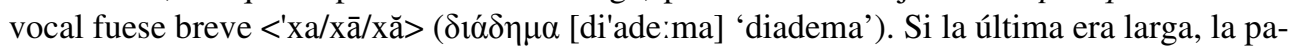
labra era llana, aunque la penúltima fuese larga o breve $<x a /{ }^{\prime} \times \bar{a} \sim ' x a ̆ / x a \bar{a}>(\gamma \varepsilon v \varepsilon \varepsilon \tau \varsigma$ [ge'nete:s] 'genitor') $)^{3}$.

En portugués y español se dan las tres posiciones (aguda, llana y esdrújula $<-$ 'xa/xa/ xa-, $-\mathrm{xa} /{ }^{\prime} \mathrm{xa} / \mathrm{xa}-,-\mathrm{xa} / \mathrm{xa} /{ }^{\prime} \mathrm{xa}->$, esp. término, termino, terminó). Ya que será una lengua de gran influencia, conviene decir que en francés, por defecto, todas son agudas $<\mathrm{xa} / \mathrm{xa} /{ }^{\prime} \mathrm{xa}>$ (salvo contadísimas excepciones).

Si bien es cierto que estas leyes de la prosodia latina y griega ya se habían olvidado al nacer las lenguas romances, la primera datación de muchas de estas voces y el tipo de léxico al que pertenecen indica que fue a través de fuentes cultas que entraron en la lengua.

\section{PROCESOS DE ADECUACIÓN}

El método de trabajo utilizado para intentar explicar esa diferente acentuación entre las dos lenguas ha sido la observación del dato etimológico, la fecha de primera documentación en cada idioma, los comentarios que aparecen sobre la prosodia en los diccionarios consultados y la aplicación de las leyes fonéticas esperables en el curso del cambio lingüístico.

Tras un estudio detallado, se observan diez procesos: (a) fidelidad a la pronunciación latina clásica, (b) adecuación al latín vulgar, (c) fidelidad a la pronunciación griega, (d) adecuación de palabra griega a la fonética latina, (e) adecuación de palabra griega al latín, con pronunciación griega, (f) influencia del francés, (g) palabras formadas por dos elementos, acento en el primero, (h) palabras formadas por dos elementos, acento en el segundo, (i) fidelidad a la acentuación de la lengua original y (j) procesos analógicos.

Esos procesos se verán ejemplificados, cada uno de ellos, con un conjunto de voces partiendo del español y dando la correspondencia portuguesa junto al proceso que ha seguido dicha lengua. Todas ellas comentadas a partir de la información ipsis litteris que

\footnotetext{
${ }^{2}$ Estas leyes, que se seguían en la prosodia latina, sobre todo, en cuestiones métricas, se veían alteradas en la lengua hablada. La cantidad breve vocálica de una sílaba larga no evitó que en el latín vulgar se pronunciase abierta, visto el resultado en las lenguas románicas. Por ejemplo, la ě — que pasó a [ع] en latín vulgar- diptongó en [je] en español; en el ejemplo dado castellum, tenemos en época medieval castiello y hoy castillo. Si la posición trabada de esa vocal hubiese dado una [e], hoy tendríamos castello*. En portugués, sin diptongación, se pronuncia [ke $\int \mathrm{t}$ lu] 'castelo'.

${ }^{3}$ La adecuación de helenismos al latín seguía las leyes de esta lengua, así $\delta$ tó $\delta \eta \mu \alpha$ [di'ade:ma], esdrújula en griego nunca lo podría ser en latín ya que la sílaba central tenía una eta (e larga) que obligaba a la posición grave 'diadēma' [dia'de:ma] en latín.
} 
ofrece cada fuente documental consultada. Se ofrecen a continuación partiendo del español y se da la correspondencia portuguesa junto al proceso que ha seguido dicha lengua.

\section{a) Fidelidad a la pronunciación latina clásica}

Las voces ofrecidas proceden de étimos latinos que han mantenido en español la pronunciación en la sílaba original, la posición esdrújula. En portugués presentan influencia del francés (f).

Tenemos la palabra 'albúmina' (1825), del latín albūmen, -̌̌nis [al'bu:men; al'bu:minis], cuyo neutro plural albumĭna se convierte en el sustantivo común a las dos lenguas. En español se mantiene la pronunciación esdrújula debido a que la i latina es breve. La voz portuguesa 'albumina' (1836) se adecua a la solución francesa (f) albumine [alby'min] (1792), según el houaiss (Dicionário Houaiss da língua portuguesa).

La voz 'límite' (1356), de lìmes, lìmütis ['li:me:s; 'li:mitis], acusativo līmütem ['li:mitem], presenta en español la misma pronunciación. En portugués 'limite' (1310) es grave, indica HOUAISs: «o voc., diferentemente do esp. e do it., não se manteve proparoxítono; em português, onde inexplicavelmente é paroxítono, observe-se, contudo, que a f. divg. linde mantém a tônica na primeira sílaba». A pesar de la fecha de primera documentación, se observan muy pocas ocurrencias en los corpus lingüísticos ${ }^{4}$ hasta el siglo XIX (con una falta de norma ortográfica, sin acentos, que no permite saber la pronunciación real); este dato podría avalar la hipótesis de la influencia francesa (f). También podría deberse a una adecuación hacia la posición grave mayoritaria heredada del latín vulgar.

Por último, el sustantivo 'régimen' (1431), del latín regĭmen ['regimen]. En portugués 'regime' (1789) presenta influencia del francés régime (f). Cabe hacer la siguiente observación: la voz latina entra en otras lenguas en dos épocas con semántica diferente. La voz francesa data de 1265 (cuando aún era inestable la norma fonética). En inglés, por ejemplo, existe desde 1400 regimen ['redzımın] con el sentido de «dieta» y regime/régime [reı'zi:m] desde 1792 con el sentido de «forma de gobierno»; la tonicidad aguda muestra que cuando la voz entró en inglés por segunda vez ya lo hizo con pronunciación aguda, la misma que influyó al portugués. En español, al documentarse tres siglos antes no le afectó.

\section{b) Adecuación al latín vulgar}

Todas las voces de este grupo proceden de étimos latinos cuya tonicidad recaía en la sílaba esdrújula (excepto dos casos, regīna y vagīna) y que en español desplazan el acento hacia la sílaba grave, posición mayoritaria de las lenguas románicas peninsulares (tras la evolución fonética propia en el paso del latín a dichos romances), independiente-

\footnotetext{
${ }^{4}$ http://www.corpusdoportugues.org, de Mark Davies; http://cipm.fcsh.unl.pt/, Corpus Informatizado do Português Medieval (CIPM)-FCSH da UNLisboa.
} 
mente de la época en que entraron en dichas lenguas. En portugués, todas respetan la tonicidad original (a).

Se presenta, en primer lugar, la voz 'alveolo' (1626), de alveŏlus [al'veolus], dim. de alvěus 'cavidad'. Se pasa de una pronunciación esdrújula a una grave. Apunta Lausberg (1982: 107):

Quando antepaenultima e paenultima consistem do grupo vocálico íě, íó, éŏ, o acento no lat. vulg. muda para a paenultima (mulíerem > muliére). [...] este fenómeno encontra a sua explicação no facto de a sensibilidade para a quantidade vocálica já ter desaparecido na altura da deslocação do acento.

Esta ley va a ser recurrente en los siguientes ejemplos, como se observará, ya que siguen el mismo modelo en español: 'aureola' (1270, de aureŏla [aw'reola], dorada), 'gladiolo' (1275, de gladiǒlus [gla'diolus], espada pequeña), 'rubeola' (1876, del lat. cien. rubeŏla [ru'beola], rojizo), 'vacuola' (1870, de vacŭum ['wakuum], vacío), 'viruela' (1250, de variŏla [wa'riola], y este del lat. varus, barro, postilla) y 'vitriolo' (1450, de vitreǒlus [wi'treolus], dim. de vitrum, vidrio). En portugués se mantiene la pronunciación original en todos los casos, fidelidad a la pronunciación del latín clásico (a). Y, generalmente, la fecha de primera aparición documentada es tardía (posterior a la española), hecho que demuestra el origen culto de los términos: 'alvéolo' 1788, 'auréola' s. xv, 'gladíolo' 1563, 'rubéola' s. XX, ‘vacúolo' s. XIX, 'varíola' 1874 y ‘vitríolo’ 1721.

No obstante, en español, en muchos casos se admite la doble acentuación, como indica el DPD (Diccionario panhispánico de dudas). Véase, por ejemplo «alvéolo o alveolo. 'Celdilla o cavidad'. La forma esdrújula alvéolo es la más cercana a la etimología y la preferida en el uso culto. Pero también se usa con frecuencia, y es válida, la forma llana alveolo [albeólo]» o «gladiolo o gladíolo. 'Planta ornamental y, especialmente, su flor'. Tiene dos formas válidas: la esdrújula gladíolo, acorde con la etimología, y la llana gladiolo, hoy mayoritaria y más recomendable».

Veremos ahora dos casos diferentes: 'cerebro' y 'reina'.

La voz 'cerebro' (1250, de cerěbrum ['kerebrum]) responde a lo que escribe Lausberg (1982: 107):

Na língua escrita o grupo consoante $+r$ (muta cum liquida) não vale como formador de posição, o acento em palavras como ténebrae, íntegrum encontra-se, por conseguinte, na antepenúltima sílaba. Ao contrário, no lat. vulg. este grupo de consoantes tem valor formativo de posição. Pronuncia-se, portanto, tenébrae, intégra > esp. tinieblas, entera.

En portugués, ‘cérebro’ (s. Xv) mantiene la pronunciación del latín clásico (a).

El sustantivo 'reina' (1140, de regīna [re:'gi:na]) sigue también la pauta de lo apuntado por Lausberg (1982: 109):

É muito frequente a deslocação do acento no hiato (primário ou secundário), onde na formação de ditongo a vogal com mais sonoridade costuma tomar sobre si o acento. Assim, entre 
outros exemplos, reíne, gaíne (< regina, vagina) são primeiro trissílabos em fr. arc. e passam a ser mais tarde dissílabos, deslocando-se o acento para a vogal mais sonora: réine, gáine (daí em fr. mod. [ręn, gęn]). De maneira semelhante deve-se interpretar a deslocação do acento em esp. réina < regína, Diós < Déus.

No así la lengua portuguesa, que es fiel a la pronunciación latina (a), 'rainha' (s. XIII). Sigue el mismo esquema 'vaina' (1240, de vagīna [wa:'gi:na]), en portugués 'bainha' (s. XIII).

\section{c) Fidelidad a la pronunciación griega}

Las voces de este grupo proceden de étimos griegos cuya tonicidad se respeta en español. En portugués, se adecuan las palabras a la pronunciación latina (d).

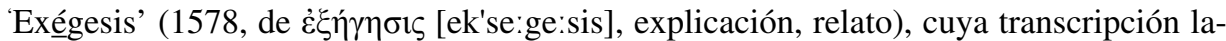
tina es exegesis, indica que debió ser pronunciada [ekse:'ge:sis] a causa de la vocal larga en la sílaba original griega - $\gamma \eta$-. En portugués, 'exegese' (1836) se adecuó a la fonética latina (d). En relación al español, el DPD dice: «exégesis o exegesis. 'Interpretación'. Ambas acentuaciones son válidas, pero el uso mayoritario y la etimología hacen preferible la forma esdrújula exégesis».

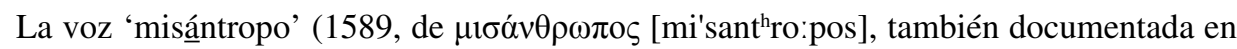
1379 sin acento), se adecua en portugués a la fonética latina (d), 'misantropo' (1789). Confirma HOUAISs:

Essa proparoxitonia tem base no padrão gr., mas se o aport. se faz através de latinização, como é de regra, então as $f$. preferenciais serão filantropo, ginantropo, licantropo, misantropo, pitecantropo, teantropo, zoantropo, paroxitonia cada vez mais aceita tanto no Brasil quanto em Portugal.

'Políglota' (1758, de $\pi$ o $\lambda v ́ \gamma \lambda \omega \tau \tau o \varsigma$ [po'lyglo:t:os]) en español y 'poliglota' (1720) en portugués, que también se adecua a la fonética latina (d). En ambas lenguas se registra la forma griega propia del Ática (frente a $\pi 0 \lambda v ́ \gamma \lambda \omega \sigma \sigma o \varsigma$, de la koiné). En español se aplica la acentuación etimológica, en portugués - y también en español-, parece que se aplica la acentuación latina (ya que la penúltima sílaba contiene una vocal larga, recae sobre ella la tonicidad). Con todo, el DPD lo atribuye a influjo francés:

poligloto -ta $o$ polígloto -ta. '[Texto] escrito en varias lenguas' y '[persona] que conoce o habla varias lenguas'. Tiene dos acentuaciones válidas: la esdrújula polígloto, acorde con el étimo griego polýglottos, y la llana poligloto [poliglóto], por influjo del francés polyglotte [poliglót] (1639). Hoy existe clara preferencia por la forma esdrújula. 


\section{d) Adecuación de palabra griega a la fonética latina}

Todas las voces proceden de étimos latinos adaptados a su vez de voces griegas. En español, se respeta la pronunciación latina, en portugués se conserva la pronunciación griega original (e).

La voz 'anatema' (1256, de anathēma [ana'te:ma], y este de $\alpha \dot{v} \alpha \theta \theta \mu \alpha$ [a'nat ${ }^{\mathrm{h}} \mathrm{e}: \mathrm{ma}$ ]) se pronuncia en español según las normas latinas, al tener la penúltima sílaba larga — como consecuencia de la $\eta-$, es grave. En portugués, 'anátema' (s. XIV) conserva la tonicidad griega (e).

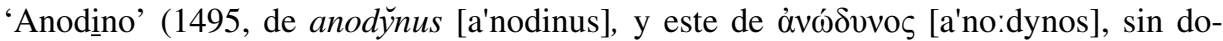

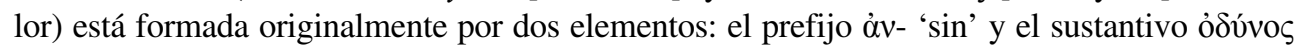
[o'dynos] 'dolor'. La lengua española parece que acentúa según el sustantivo original, mientras que el portugués ‘anódino' (1605) mantiene la acentuación griega del adjetivo resultante.

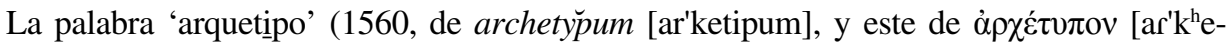
typon], influenciado en su acentuación por el fr. archétype [arke'tip] — S. XIII-), en nuestra opinión, ha sufrido un cambio de tonicidad hacia la i (grave) por analogía con 'tipo', (de ty̆ el mismo patrón en español daguerrotipo (1842), estereotipo (1961) y logotipo (1975) —formados por dos elementos-, que en portugués se hacen analógicos con arquétipo (1537), — daguerreótipo (1836), estereótipo 1961), logótipo (s. XX )— con pronunciación griega (e).

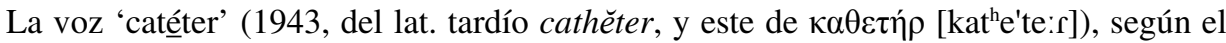
étimo, debería ser ['kateter], pero posiblemente ya se pronunció [ka'teter] desde los inicios, adecuando la palabra a la posición llana dominante. Para el portugués 'cateter' (1836), se lee en HOUAISs: «a pronúncia postulada pelo étimo é oxítona, us. pelos médicos mais cultos, mas a predominante, pelo menos no Brasil, é a paroxítona catéter/catéteres; em Portugal, a registrada como correta é igualmente a culta». Pronunciación griega (e).

Para 'crisantemo' (1797[1557], de chrysanthĕmum [kri'sa:ntemum], y este de $\chi \rho v \sigma \alpha ́ v \theta \varepsilon \mu$ ov [k $\left.\mathrm{k}^{\mathrm{h}}{ }^{\prime}{ }^{\prime} \mathrm{ant}^{\mathrm{h}} \mathrm{emon}\right]$; propiamente 'flor de oro'), nos avenimos a las mismas razones que para catéter. El portugués ‘crisântemo’ (1858) pronuncia a la griega (e).

La voz 'elogio' (1488, de elogŭum [e'logium], y este de $\varepsilon v ̉ \lambda o \gamma i ́ \alpha$ [ewlo'gia], alabanza) aplica en su tonicidad las reglas latinas en español. En portugués, 'elogio' (1603) mantiene la pronunciación griega (e).

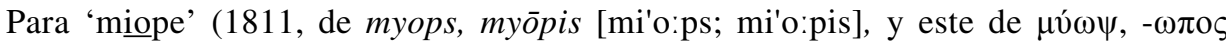
['myo:ps; 'myo:pos], 'que parpadea para ver mejor'), en español, la ō obliga a la posición grave, a partir del acusativo myōpem [mi'o:pem]. En portugués, 'míope' (1813) mantiene la tonicidad griega (e). Dice houaiss: «gr. múóps,ópos 'que pisca os olhos para ver melhor', pelo lat.tar. mýops, òpis 'que tem a vista curta, que pisca os olhos', com recuo da tônica».

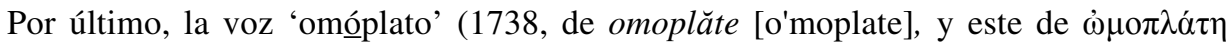
[o:mo'plate:]). La vocal breve latina en la segunda posición obliga a la pronunciación esdrújula, mantenida en español; portugués 'omoplata' (1695), sigue el patrón griego (e). 


\section{e) Adecuación de palabra griega al latín, con pronunciación griega}

En este grupo, las voces ofrecidas proceden de étimos latinos que fueron tomados a su vez del griego. En español se conserva, a pesar de esa circunstancia, la pronunciación griega, en tanto que en portugués presentan la tonicidad del latín (d).

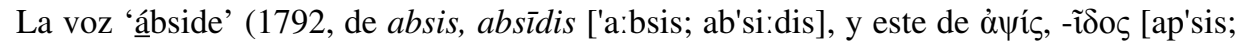
ap'si:dos], nudo o clave de la bóveda) y la portuguesa 'abside' (1850), proceden del acusativo singular absìdem [ab'si:dem]. En lo referente a la acentuación, español parece que prefiere la tonicidad sobre la sílaba esdrújula por el nominativo latino ['a:bsis], y portugués sigue la pronunciación griega (d).

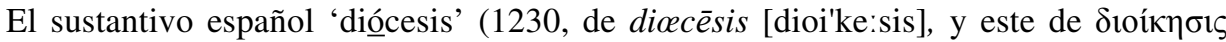
[di'oike:sis], 'gobierno de la casa') se atiene a la pronunciación griega. En portugués, 'diocese' (s. xv) respeta la fonética latina (d).

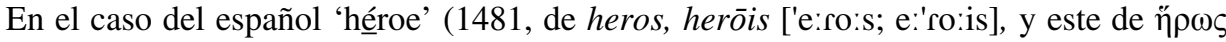
['he:ro:s], jefe, noble, héroe), procedente del acusativo singular latino herōem [e:'ro:em], prefiere la referencia al nominativo, en tanto que la forma portuguesa 'herói' (s. xv) adecua la palabra griega al latín (d).

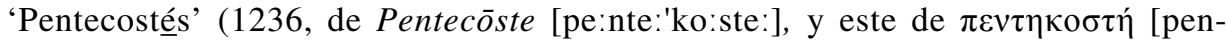
te:kos'te:], t. f. de - $\tau$ ós, quincuagésimo) respeta la pronunciación del griego; el portugués 'Pentecostes' (s. XIV), la latina (d). La acentuación grave del latín responde a la posición de la $\bar{o}$, ante dos consonantes, por lo tanto, grave.

La voz 'síntoma' (1490), de symptōma [si:mp'to:ma], y este de $\sigma u ́ \mu \pi \tau \omega \mu \alpha$ ['sympto:ma], infelicidad, mala suerte) mantiene la tonicidad griega. La voz portuguesa 'sintoma' (1661) se atiene a la solución latina (d) - la vocal larga ō obliga a la acentuación grave-

\section{f) Influencia del francés}

Todas estas voces, procedentes de étimos latinos (salvo dos casos, acné y amalgama) han sufrido la influencia de la lengua francesa en su adaptación fonética al español. En portugués, se muestran fieles a la pronunciación original $(\mathrm{a} / \mathrm{i})$.

La palabra 'acné' (1919, del fr. acné [ak'ne] —1816-, y este del gr. óx $\chi{ }^{\prime} \eta$ ['ak'ne:], película, eflorescencia) se pronuncia en español como en francés. En portugués, 'ạcne' (1891) respeta la tonicidad de la lengua original, en este caso, el griego (i).

La siguiente voz es 'amalgama' (1569, del b. lat. amalgama). El GDLC (Gran Diccionari de la Llengua Catalana) afirma que entró en la lengua catalana a través del francés amalgame [amal'gam], hecho que explicaría la pronunciación grave también en español. En francés es un préstamo de la lengua árabe. El TLFI (Le Trésor de la langue française informatisé (1971-1994)) apunta: «De l'arabe amal al-gamāa (œuvre de l'union charnelle) composé de عمل, 'amal (œuvre, faire), المع jâma'a (unir, réunir, copuler)». La pronun- 
ciación del árabe actual es esdrújula, y así se pronuncia en portugués, 'amálgama' (s. XVIII) (i).

El adjetivo español 'imbécil' (1519, de imbecīllis [imbe'ki:l:is], sin inteligencia) debe su tonicidad a una mala interpretación de la grafía francesa —en francés, la 'é' en este caso no indica tonicidad, informa apenas de que la vocal ha de ser pronunciada [e] y no [ə]—. El GDLC así lo confirma para el catalán, mismo fenómeno que en español, y dice: «la forma imbècil prové de la grafia francesa imbécile [z̃be'sil] (1496) mal interpretada».

La voz 'misill' (1490, de missillis ['mis:ilis], arrojadizo) merece para el DPD la siguiente observación (repárese en que se contraría en el dato etimológico con el DRAE):

misil o mísil. 'Proyectil autopropulsado'. Del inglés missile (y este del lat. missilis 'arrojadizo'), tiene dos acentuaciones válidas en español. Aunque la forma llana mísil está más cerca de la pronunciación inglesa, resulta preferible la forma aguda misil [misíl], de probable influjo francés, por ser la más extendida en el uso de todo el ámbito hispánico.

En francés, missile [mi'sil], se fecha en 1840. En portugués 'míssil' (1881) mantiene la tonicidad del latín — la $\breve{~ o b l i g a ~ a ~ q u e ~ l a ~ v o z ~ s e a ~ e s d r u ́ j u l a ; ~ g r a v e ~ p o s t e r i o r m e n t e ~ e n ~ p o r t u-~}$ gués- (a).

Siguen el mismo patrón 'proyectil' (1762), 'reptil15' (1400) y 'textill' (1427[1868]). En portugués, 'projẹetil' (1789[1813]), 'réptil' (1813) y 'tệxtil' (1899).

Por último, la palabra 'termita' (1893, del fr. termite [tєR'mit] (1797), y este del lat. termes, termittis ['termes; 'termitis]). En portugués, 'térmite' (1899), con pronunciación latina (a).

\section{g) Palabras formadas por dos elementos, acento en el primero}

Se tratan en este grupo voces que resultan de la unión de dos palabras griegas, cada una con su tonicidad. La nueva palabra, en español toma el acento de la primera voz. En portugués, se produce el fenómeno contrario, toma el acento de la segunda.

La voz española 'atmósfera' (1578) y la portuguesa 'atmosfera' (1717), procedentes del lat. cient. atmosphāēra [atmos'faera], y este del gr. ả $\tau \mu$ ó $\varsigma$ [at'mos] 'vapor, aire' y $\sigma \varphi \alpha i ̃ \rho \alpha$ [s'faira] 'esfera', indican que el español toma el acento de $\alpha \tau \mu$ ó $\varsigma$ y portugués de $\sigma \varphi \alpha \tilde{\rho} \alpha$.

'Megáfono' (1930) en español y 'megafone' (s. xx) en portugués —ambas de $\mu \varepsilon ́ \gamma \alpha$ ['mega], que da el prefijo $\mu \varepsilon \gamma \alpha-$ 'grande' y '- $\varphi \omega v o \varsigma$ [p $\mathrm{p}^{\mathrm{h}}$ onos] 'sonido', sobre el modelo de à $\varphi \omega v o \varsigma$ 'sin voz' - indican el mismo proceso: español acentúa a partir de la primera pa-

\footnotetext{
5 DPD: reptil. 'Animal que repta'. Procede del latín reptilis [rréptilis], que se acentuaba en la primera sílaba. Sin embargo, la única forma vigente en el español actual es reptil [rreptíl], con acentuación aguda debida seguramente al influjo del francés (reptile [Rep'til] 1304). La forma llana réptil ha caído en desuso y debe evitarse.
} 
labra y portugués de la segunda. Dice el DRAE en relación al sufijo '-fono lo siguiente: «Del gr. '- $\varphi \omega v o \varsigma<\varphi \omega v \eta ́$ [p $\left.\left.{ }^{\mathrm{h}} \mathrm{o}^{\prime} \mathrm{ne}:\right]\right)$ 'voz', 'sonido'». Por su parte HOUAIss, partiendo de la misma etimología, apunta:

-fone. [...] aparece em uns quantos neologismos do siglo xix para cá (aerofone, copofone, fone, gramofone, heptafone, hidrofone, hipnofone, interfone, linguafone, megafone [...]; em função de telefone e do fato de que em esp. o neologismo (de 1887) se consagrou como teléfono (acentuação potencial gr., favorecida pelo homólogo telégrafo), houve dúvida, em port., quanto à acentuação tônica - razão por que se buscou superar os dois escolhos; o fato é que o padrão -fone paroxítono, absolutamente conforme ao -ó- gr., acabou prevalecendo.

Siguen el mismo patrón teléfono y micrófono.

'Teléfono' (1870) y ‘telefone' (1874), de tele- y -'fono. 'Micrófono' (1870) y 'micro-

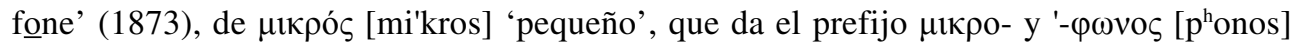
'sonido'.

La palabra española 'píloro' (1738) y la portuguesa 'piloro' (1695) proceden de PYLōRUS [pi'lo:rus], y este de $\pi v \lambda \omega \rho o ́ \varsigma$ [pylo:'ros], portero. La palabra griega se formó a través de $\pi v ́ \lambda \eta$ 'puerta' y $\omega \rho \alpha$ 'cuidado, preocupación'. Portugués mantiene la pronunciación latina, español opta por la tonicidad esdrújula, partiendo del sustantivo griego $\pi v ́ \lambda \eta$.

\section{h) Palabras formadas por dos elementos, acento en el segundo}

Se tratan en este grupo voces que resultan de la unión de dos palabras griegas (salvo un caso árabe), cada una con su tonicidad. La nueva palabra, en español toma el acento de la segunda voz. En portugués, se produce el fenómeno contrario, toma el acento de la primera.

En primer lugar, el término 'aerolíto' (1847), en portugués 'aerólito' (1818), proceden-

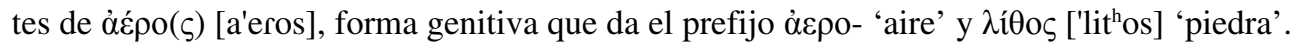

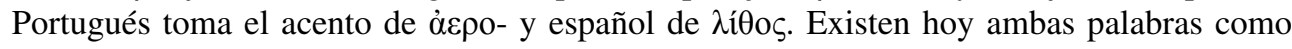
prefijos y sufijos para formar neologismos lito-, -lito, hecho que ha producido una analogía en español con esas voces acabadas en -lito, todas ellas graves. Siguen el mismo patrón megalito y monolito.

'Megalito' (1880) y 'megálito' (s. Xx), DE $\mu \varepsilon \dot{\gamma} \alpha$ ['mega], que da el prefijo $\mu \varepsilon \gamma \alpha-$ y $\lambda i ́ \theta o \varsigma$ ['lit ${ }^{\mathrm{h}} \mathrm{os}$ ] 'piedra'. 'Monolito' (1839) y 'monólito' (1858), de monolĭthus [mo'nolitus], y este de $\mu$ ovó $\lambda 1 \theta$ os [mo'nolit $\left.\left.{ }^{\mathrm{h}} \mathrm{os}\right]\right)$. En griego, esta voz procedía a su vez de $\mu$ óvos 'único' y $\lambda i ́ \theta$ os 'piedra'.

Las voces 'alcoholl' (1200) y ‘álcool' (1691) son descendientes del ár. hisp. [al-]kuhuúl, y este del ár. clás. [al-]kuḥl الكحول. La lengua portuguesa carga la tonicidad sobre el artículo árabe aglutinado.

El par 'electrodo' (1881) y 'elétrodo' (1873), del fr. électrode [elck'trod] (1838), este

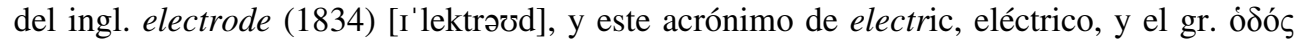




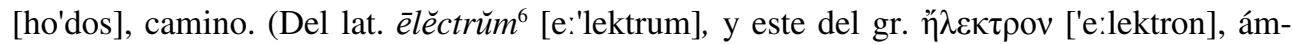
bar). En español se mantiene la pronunciación francesa; en portugués predomina la del latín èlěctrŭm (cf. eléctrico).

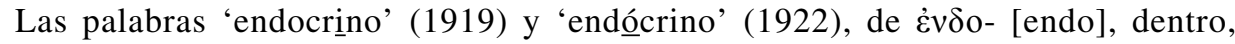
y крíveıv ['krinin], separar. Portugués acentúa en el prefijo, español mantiene el acento de la palabra originaria griega.

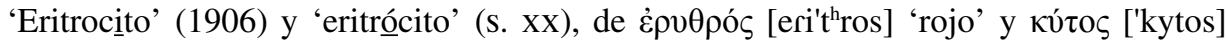

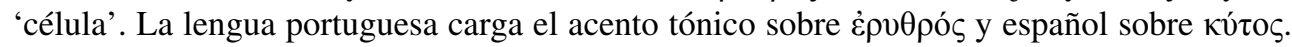
Siguen el mismo patrón 'leucocíto' (1870) y 'leucócito' (1873), de $\lambda \varepsilon v \kappa o ́ \varsigma ~[l e w ' k o s]$

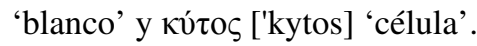

Las palabras 'isobara' (1900) e 'isóbara' (1899) procedentes del fr. isobare [izo'bar] (1875), y este de i $\sigma o \beta \alpha \rho n ́ s$ [isoba're:s], de igual peso. La palabra griega procede, a su vez, del prefijo iøo- 'igual' (su acentuación depende de la palabra siguiente) y ßà

'Petroglifo' (1953) y 'petróglifo' (s. xx), de $\pi \varepsilon \tau \rho o-$ [petro] < $\pi \varepsilon ́ \tau \rho \alpha$ 'roca' y un der. $-\gamma \lambda \cup \varphi \varsigma\left[\mathrm{glyp}{ }^{\mathrm{h}} \mathrm{os}\right]$, del verbo que significa 'cincelar, grabar'. Portugués acentúa sobre la forma $\pi \varepsilon \tau \rho \circ-\mathrm{y}$ español sobre - $\gamma \lambda \nu \varphi \circ \varsigma$.

Finalmente, las voces ‘termostato' (1940) y ‘termóstato’ (s. Xx), derivadas de $\theta \varepsilon \rho \mu o ́ c$, que da el prefijo $\theta \varepsilon \rho \mu$ o- [thermo] 'calor, caliente' y $\sigma \tau \alpha \tau o ́ s$ [sta'tos] 'estable'. Portugués acentúa en $\theta \varepsilon \rho \mu o-$ y español en $\sigma \tau \alpha \tau o ́ s$ con mudanza de acento, hacia la grave (posición mayoritaria).

\section{i) Fidelidad a la acentuación de la lengua original}

Este grupo está formado por voces que proceden de diferentes lenguas y que en español han mantenido la tonicidad del original. En portugués presentan dos soluciones: influencia del francés (f) o procesos analógicos (j).

La voz española 'angora' (1785[1916], de Angora, ant. nombre de Ankara, ciudad de Turquía) mantiene la pronunciación grave. En portugués, 'angorá' (1949[angora 1871]) se pronuncia a la francesa (f). Léase HoUAISs, que manifiesta lo siguiente:

top. Ancara + -ense; o geônimo tem orig. antigas, expressas no gr. Ánkyra, lat. Ancýra; já nessas orig. a flutuação tônica se justificaria, quer segundo o padrão gr. Âncara, quer segundo o padrão lat. Ancara; a forma tradicional port. também é flutuante, próxima do lat. em Angora $e$ sob infl. fr. em Angorá (1761).

La palabra 'caníbal' (1492, de caríbal, de caribe) mantiene la pronunciación de la lengua original americana. En portugués, 'caniball' (1727) se pronuncia a la francesa (f), según sostiene HOUAISs: «esp. alteração de caríbal, der. de caribe 'ousado, audacioso', voc. indí-

${ }^{6}$-lěc-, vocal breve en sílaba larga. 
gena das Antilhas e que serviu para designar o povo caraíba; na mudança da tônica, deve ter influído o fr. cannibale [kani'bal] (s. XVI)».

El sustantivo 'icono' (1490, de icône [i'kon] (1208), este del ruso ikona <икона>

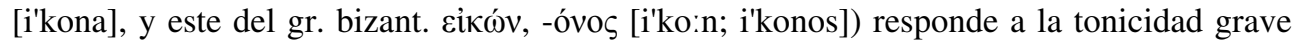
original. Al respecto, apunta el DPD:

Tiene dos acentuaciones válidas: la llana icono (pron. [ikóno]) es la más próxima a la etimología (del gr. bizantino eikón, -ónos, a través del fr. icône) y la de uso mayoritario en España; en América, en cambio, se usa más la esdrújula ícono. Debe evitarse en español el uso de la variante femenina icona, debida probablemente al influjo del italiano <icona> [i'kona].

En portugués, 'ícone' (1914) muestra tonicidad esdrújula, seguramente debido al inglés (icon/ikon ['arkpn] 1570) ya que en su acepción semiológica entró a través de esta lengua (HOUAISS, 2001) (j).

El sustantivo español 'nivelel' (1377) y el portugués 'nível' (1517) proceden, según el DRAE del provenzal y HOUAISs dice que proceden del francés antiguo «nivel (s. XIV, atual niveau [ni'vo]) 'id.', de livel (s. XIII) 'id.' e este, do lat.vulg. *libellus pelo lat.cl. libĕlla [li'bel:a] 'nível 'instrumento com que se verifica o nível', dim. de libra,ae 'balança'». En cualquier caso, no se aclara la pronunciación grave del portugués.

Juzgamos que se ha producido una posible analogía con todas las palabras acabadas en -ável, -ével e -ível, muy numerosas como adjetivos y sustantivos (amável, candidatável, indelével, incrível...) —el -ble español—. Siguen el mismo patrón 'desnivel' (1598) y 'desnível' (1878) (j).

La voz 'océano' (1223, de oceănus [o'keanus], y este de ' $\Omega \kappa \varepsilon \alpha v o ́ \varsigma$ [o:kea'nos]; mitología: uno de los doce titanes) mantiene la acentuación latina (sobre la -e-), el portugués la ha cambiado (sobre la -a-). Dice HouAIss: «antepositivo, do gr. Ókeanós, ô̂ 'Oceano, [...] pelo lat. Oceànus, $i$; ocorre em oceano (s XIV) e oucião (s. XIV), com deslocamento do acento tônico por analogia com o grande número de subst. em -ano.» (j).

El sustantivo 'pantano' (1526, del it. pantano [pan'tano] (1310); quizá voz prerromana en el nombre Pantānus [pan'ta:nus], cierto lago de Italia antigua. En la Apulia, hoy el lago se llama Lesina) conserva la tonicidad original. Es de difícil explicación la acentuación esdrújula de la palabra portuguesa 'pântano' (1644). Quizás hubo analogía con la palabra pâmpano (1574) —pámpano, en español—, término usual en el campo (j).

Es interesante la siguiente reflexión de Correas (1625: 386) que nos da pistas fiables de la pronunciación ya en el siglo XVII de algunas de estas voces:

El barbarismo es barbara manera de hablar, i consiste en mal conzierto de las rrazones, ó mesclando en la orazion palabras incognitas de alguna lengua barbara, $i$ en vizio de mal pronunciar i escribir, quitando, añidiendo, ó duplicando, ó trocando letra, ó silaba, ó azento en la

7 -b̌̌-, vocal breve en sílaba larga. 
dizion, como diziendo virtu por virtud, zidad por ziudad, amanesze por amaneze, ansin por asi, curto por corto, brenbillo por menbrillo, drento, trenpano por dentro, tenprano, pávilo, pántano con el azento en la primera por pavilo, pantáno con él en la de medio, ozeáno con el azento en la penultima por azéano en la antepenultima, i otras barbariedades que vemos en Moriscos, $i$ negros i extranxeros rrezien venidos.

\section{j) Procesos analógicos}

En este grupo, aparecen voces diseminadas, procedentes de diferentes lenguas, que difieren de la pronunciación de la lengua original en español; se adecuan a través de la analogía con alguna de las soluciones vistas en los grupos precedentes. En portugués presentan diversas soluciones: fidelidad al latín clásico (a), a la lengua original (i) o procesos, también, analógicos (j).

El sustantivo 'alcazába' (1290, del ár. hisp. alqașába, y este del ár. clás. qáṣabah) mantiene la tonicidad del árabe hispánico. La voz portuguesa 'alcáçova' (s. XV) es fiel a la pronunciación del árabe actual [al-]qáṣbah القصبة (i).

La voz ‘alguien' (1218), del latín alı̆quem ['alikwem], acus. de alı̆quis < alis + quis, responde a lo que escribe Penny (1993: 149):

aliquis se reforzó mediante su combinación con unus: aliquis ünus, de donde algun(o), expresión normal del castellano medieval tanto para 'algo/nada' como para 'alguien'. En el siglo xv aparece un competidor alguién (así acentuado) — variante de alguno explicable a partir de quien-, que lo sustituyó más tarde en el sentido de 'alguien'; alguién sufrió un desplazamiento del acento a alguien, quizá por imitación del modelo acentual de algo.

En portugués la acentuación se decantó por la sílaba aguda (analogía con ninguém), por tanto, proceso analógico (j).

Toda la familia léxica formada con el sufijo '-crata. El DRAE escribe: «Quizá del fr.

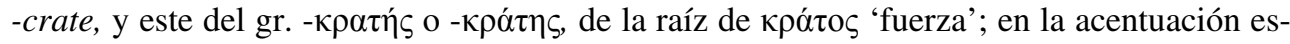
drújula española influyeron ciertos nombres propios latinos como Aristocrătes 'Aristócrates' o Democrătes 'Demócrates'». En portugués domina la solución grave. Algunos ejemplos: 'aristóccrata' (1810) / 'aristocrạta' (1837); 'burócrata' (1876) / 'burocrạta' (1863) y 'demócrata' (1857) / 'democrata' (1799).

La voz 'canguro' (1853, del fr. kangourou [kãgu'Ru], y este de or. australiano) se adecua en español a la posición grave, natural de las lenguas románicas peninsulares. En portugués, 'canguru' (1838) se pronuncia a la francesa. El término entró en francés (1774) a través del inglés kangaroo [kængə'ru:] (1770), en su forma antigua kangooroo, de gangurru, de un idioma nativo de Australia. Confirma HouAIss que: «JM e Nasc. narram que não há essa palavra nativa naquela região e que talvez a palavra em inglês tenha surgido de um equívoco do capitão Cook com relação às palavras nativas para "não sei" ou "não entendi você"».

El sustantivo 'cónclave' (1400, de conclāve [ko:n'kla:we], lo que se cierra con llave, de cum y clavis) se documenta en los diccionarios académicos españoles desde el Diccionario 
de Autoridades (1726-1739), escrito 'conclave'; el DRAE 1780 (1. a ed.) recoge 'cónclave'. Desde 1884 (12. ${ }^{\text {a }}$ ed.) hasta 1992 (21. a ed.) se aceptan ambos (con preferencia por la forma llana) pero DPD dice: «cónclave. 'Junta de cardenales para elegir nuevo papa'. Hoy solo se usa la forma esdrújula cónclave. La etimológica llana conclave ha caído en desuso y debe evitarse». En portugués, 'conclave' (s. XV) es fiel a la pronunciación latina clásica (a).

La voz 'disparr' (1400, de dispar, dispăris ['dispa:r; 'disparis]) se pronuncia de modo analógico a par. En portugués, 'díspar' (1519) mantiene la pronunciación latina original (a). Véase: 'impar' (1428, de impar, impāris ['impar; im'pa:ris]), 'ímpar' (1519), que siguen el mismo proceso.

El vocablo español ‘élite' (1845 —elite, 1893-) y el portugués 'elite' (1871) proceden del fr. élite, participio pasado antiguo (eslite) de élire, lat. vulgar esligere del clásico elegere 'escoger'. Ambas lenguas siguen la pronunciación francesa (i), no obstante para el español, el DPD DICE:

élite $o$ elite. Ambas acentuaciones son válidas. La voz francesa élite, que significa 'minoría selecta o rectora' y se pronuncia en francés [elít], se adaptó al español en la forma llana elite [elíte]; pero la grafía francesa élite (1176), que circuló como extranjerismo durante un tiempo, dio lugar a que muchas personas pronunciasen esta voz francesa interpretando la tilde a la manera española, es decir, como palabra esdrújula. Aunque esta pronunciación es antietimológica, es hoy la más extendida incluso entre personas cultas; por ello, la grafía élite y la pronunciación esdrújula correspondiente se consideran también correctas.

Es lo mismo que ocurrió con imbécil.

El adjetivo 'impío' (1200) según el DRAE procede: «De impǔus ['impius], con el acento de pío < lat. pius ['pius]». Esa razón no sirve para el portugués 'ímpio' (1563) que mantiene la pronunciación latina (a).

El adjetivo 'impúdico' (1438, de impudīcus [impu'di:kus]) presenta una tonicidad analógica con los adjetivos acabados en -ico esdrújulos. En portugués, 'impudico' (1540) es fiel a la pronunciación latina (a). HOUAISs dice que: «trata-se de um dos poucos adj. em port. (excluídos os dissílabos) com a terminação -ico paroxítona». HOUAISs aporta la siguiente información:

-íco: dim. -ico (do lat.vulg. -icu-/-iccu-), desde as orig. da língua: abanico, amorico, bailarico, burrico, copico, demonico, maçanico, milico, mulherico, nanico, panico, papelico, pelico, santico, testico, veranico, vilancico.

'-ico: formador de adjetivos, do gr. -ikós,ê,ón: 1) ocorre em lat. -ìcus,a,um de forma algo parcimoniosa, difundindo-se a partir do Renascimento como, talvez, o suf. culto por excelência para a form. de adjetivos, em todas as línguas român. (it.port.esp. -ico, fr. -ique), em que (salvo para com o fr., estruturalmente) é sempre proparoxítono (pois seu i, em gr. como em lat., é breve); segue-se um exemplário não exaustivo: acústico, aeróbico, alcoólico, alfabético, anárquico, anêmico, anímico, arábico, arcádico, atávico, balístico...

Sigue el mismo esquema el adjetivo 'púdico' (1400, de pudīcus [pu'di:kus]), en portugués 'pudico' (1525). 
El vocablo 'médula' (1411 —medula 1376_, de medūlla [me'du:1:a]) se pronuncia desde antiguo esdrújulo. Leemos en el DPD: «médula o medula. 'Sustancia que se halla en el interior de los huesos'. Aunque la forma llana medula (pron. [medúla]) es la que conserva la acentuación etimológica, la forma esdrújula médula es hoy mayoritaria y, por ello, preferible».

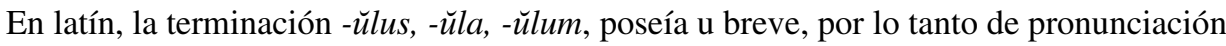
esdrújula. El caso que nos ocupa, al presentar una consonante geminada, confería a la u una cantidad larga, siendo su pronunciación grave. El español actual ha optado por el proceso analógico (báscula, cláusula, clavícula, fábula, fístula, libélula, matrícula, mayúscula, molécula, partícula, película, península, úvula...) y ha dotado a la voz de una doble posibilidad acentual. En portugués, 'medula' (1561) respeta la posición de la tónica latina (a).

Para el sustantivo 'pelícano' (1350, de pelicānus [peli'ka:nus], y este de $\pi \varepsilon \lambda \varepsilon \kappa \alpha ́ v$ [pele'kan]), véase lo que apunta el DPD:

pelícano. 'Ave acuática con una especie de bolsa en el pico'. Aunque en latín era voz llana (lat. pelicanus, pron. [pelikánus]), hoy solo se usa en español con acentuación esdrújula, lo que permite diferenciar este sustantivo del adjetivo pelicano ('de pelo cano').

Con todo, el DRAE sigue admitiendo ambas entradas. En portugués, 'pelicano' (1507) se respeta la fonética de la lengua de que procede (a).

Y por último, la voz 'róbalo' (1605 —robạlo 1381—). El DPD apunta:

robalo o róbalo. 'Pez de carne muy apreciada, más comúnmente llamado lubina'. Esta voz, formada por metátesis de lobarro (derivado del latín lupus 'lobo', que se aplicó metafóricamente a este pez), tiene dos acentuaciones válidas: la etimológica llana robalo [rrobálo] y la esdrújula róbalo (quizá por influjo del pez llamado sábalo).

En portugués, 'robalo' (1595).

Por último, cabe hablar en estas líneas del numerosísimo grupo de palabras griegas aca-

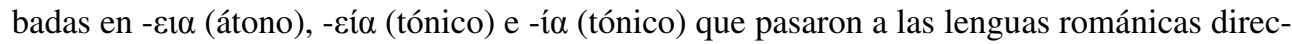
tamente o a través del latín bajo la forma -ia (átono así escrito en español; átono y tónico así escrito en portugués) o -ía (tónico así escrito en español). Sirvan estos dos ejemplos:

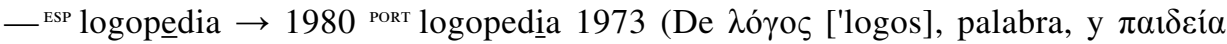
[pai'dia], educación).

— ${ }^{\mathrm{ESP}}$ policía 1405-1828 (sentido actual) $\rightarrow{ }^{\text {PORT }}$ polícia s. XV (DE politīa [poli'tia], y

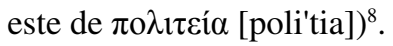

8 Véase el estudio «El policía y o polícia: la adaptación de helenismos acabados en -ía/-ia que generan diferente pronunciación en español y portugués» (VÁZQUEZ DIÉGUEZ, 2013). En él, se clarifica que la fecha de entrada en la lengua, la presión de la lengua culta y los criterios del latín científico marcaron el devenir de cada palabra en las diferentes lenguas románicas. Las que corresponden al diccionario esencial son: abulia, academia, acracia, afasia, alcoolemia, alergia, alopecia, ambrosía, anemia, anestesia, anorexia, antropofagia, aristo- 


\section{OTROS CASOS}

Se incluyen aquí, de manera muy somera, cuestiones relativas a toponimia, onomástica y a verbos.

\section{a) Toponimia, algunos casos comunes}

${ }^{\text {ESP }}$ Bombay / ${ }^{\text {PORT }}$ Bombaim. Que en portugués se pronuncie con hiato responde a la dicción del maratí, lengua oficial del estado de Maharashtra, cuya capital es la ciudad en cuestión. A través del hindi o del inglés ha pasado a la mayoría de lenguas con pronunciación diptongada. Según el DPD: «Bombay. Forma tradicional española del nombre de esta ciudad de la India. Aunque actualmente la denominación oficial de esta ciudad ha adoptado la forma local Mumbai, sigue siendo preferible en español el uso del topónimo tradicional».

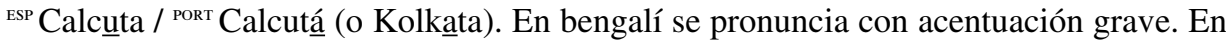
relación a la grafía con 'a' del portugués, son interesantes las siguientes palabras de Corominas (1964: 56):

Hauriem de dir [...] Bombaí, Calcata, Panjab, Samatra. Tinguem en compte que els anglesos escriuen Calcutta, Punjab, Sumatra, precisament amb l'intent que hom pronuncï Calcata, Panjab, Samatra, com de fet ho fa tothom que sap pronunciar l'anglès, i és com es pronuncia unànimement en les llengües originals. Però aquí escaurà d'indicar que en algun d'aquests noms segurament ja no som a temps a fer rectificar la forma errada: ¿aconseguirem de desterrar Calcuta i Bombai per més erronis que siguin? Temo molt que no. Potser valdria la pena de provar-ho, tal com ho han fet amb èxit els portuguesos $i$ àdhuc els italians.

La forma aguda portuguesa, más antigua en la lengua, podría deberse a la analogía con Calicut. A ambas ciudades llegaron los portugueses en el siglo XVI y tuvieron allí relaciones comerciales.

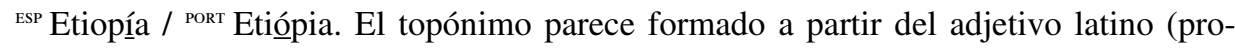

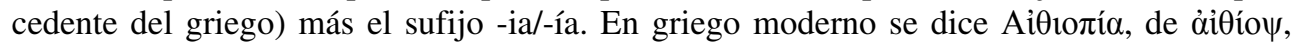

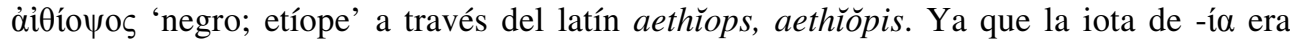
breve, pasa al latín como i breve y por lo tanto como voz grave. En portugués se mantiene la acentuación griega, en español, la latina.

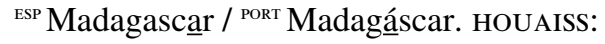

cracia, arritmia, asfixia, claustrofobia, demagogia, democracia, epidemia, epilepsia, euforia, fisioterapia, fobia, halterofilia, hemiplegia, hemofilia, hemorragia, hipertrofia, idiosincracia, leucemia, lipotimia, magia, metalurgia, misoginia, nostalgia, ortodoxia, ortopedia, periferia, pirotecnia, poligamia, polisemia, quimioterapia, quiromancia, radioterapia, siderurgia, sinestesia, tauromaquia, terapia y xenofobia. Todas ellas pronunciadas sobre la -i- (hiato) en portugués.

Las siguientes voces: acrobacia, alquimia, biopsia, burocracia, difteria, diplomacia, dislexia, embolia, etnia, filatelia, oligofrenia, ortodoncia, taquicardia y telequinesia, a pesar de no presentar la terminación en causa en la voz griega, acaban, por analogía, formando parte de este grupo. 
Madagáscar, paroxítona, adotada em Portugal, já se registra nos Lusíadas (X, 137, 8); Madagascar, oxítona, seria preferível pela analogia com numerosos oxítonos em -ar da língua portuguesa, dentre os quais outros nomes de orig. malaia, como Zanzibar, Malabar, Macassar, todos pronunciados com acento oxítono.

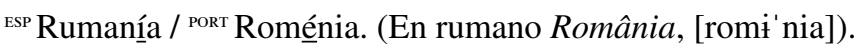

EsP Sofía / ${ }^{\text {PoRT }}$ Sófia. (En búlgaro Сoфия ['sofije]).

\section{b) Onomástica, algunos nombres conocidos}

EsP Cicerón / ${ }^{\text {PORT }}$ Cícero. (En latín, —nominativo- Cicero ['kikero:]; —acusativo- Cicerōnem [kike'ro:nem]). La solución portuguesa procede del nominativo.

${ }^{\text {ESP }}$ Cleopạtra / ${ }^{\text {PORT }}$ Cleópatra. (En griego K $\lambda \varepsilon o \pi \alpha ́ \tau \rho \alpha$ [kleo'patra]). Este nombre procede

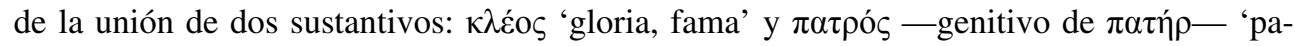
dre': 'la gloria del padre'. En español se respeta el acento tónico de la nueva voz (sobre la forma del genitivo), en portugués se ha desplazado a la sílaba anterior, sobre el nombre $\kappa \lambda \varepsilon ́ o \zeta$.

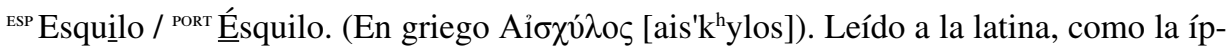
silon es breve, pasa el acento a la posición esdrújula, solución del portugués. El español sigue el modelo griego.

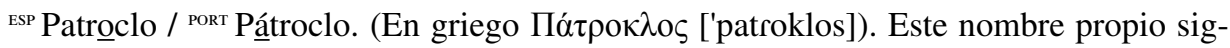
nifica lo mismo que Cleopatra, 'la gloria/fama del padre'. La colocación de las palabras griegas $\kappa \lambda \varepsilon$ ć $\varsigma$ 'fama, gloria' y del genitivo $\pi \alpha \tau \rho$ ó $\varsigma$ 'del padre' se produce al contrario que el de la famosa reina egipcia helenizada. En este caso, el portugués acentúa sobre el genitivo y el español sobre la palabra 'fama'.

Este diferente orden en griego, ya que las palabras son las mismas, debe responder al hecho de aplicarlo a una mujer o a un hombre.

\section{c) Verbos acabados en -iar y -uar}

En español, los presentes de indicativo y subjuntivo de los verbos acabados en -iar siguen un doble modelo, pronunciados con hiato o con diptongo (salvo primera y segunda personas del plural que siempre se pronuncian con hiato). En portugués hay un único modelo, siempre con hiato. Ej. cambio o esquío / cambịo, esquío.

Se verifica en español una alternancia acentual en los presentes (indicativo y subjuntivo) de los verbos acabados en -uar (salvo primera y segunda personas del plural): adécuo o adecúo. En portugués, siempre con hiato: adequo. 


\section{CONSIDERACIONES FINALES}

Tras el análisis efectuado en el conjunto de palabras ofrecidas, se repara en los siguientes hechos:

— cuando el español es fiel a la pronunciación latina clásica (a), el portugués se decanta por la influencia del francés (f), ex: albúmina / albumina,

- cuando el español adecua la pronunciación al latín vulgar (b), el portugués invariablemente muestra fidelidad a la pronunciación latina clásica (a); ex: cerébro / cérebro,

— cuando el español mantiene la pronunciación griega (c), el portugués adecua la pronunciación griega al latín (d); ex: misántropo / misantropo,

— cuando el español adecua la palabra griega a la fonética latina (d), el portugués la adecua al latín pero con pronunciación griega (e); ex: arquetipo / arquétipo,

- cuando el español adecua la palabra griega al latín con pronunciación griega (e), el portugués adecua la palabra griega directamente a la fonética latina (d); ex: héroe / herói,

— cuando el español acepta la influencia del francés (f), el portugués opta mayoritariamente por ser fiel a la pronunciación de la lengua original $(\mathrm{a} / \mathrm{i})$; ex: reptil / réptil amalgama / amálgama,

- cuando el español acentúa en el primer elemento de voces formadas a partir de dos (g), el portugués invariablemente acentúa en el segundo elemento; ex: atmósfera / atmosfera,

— cuando el español acentúa en el segundo elemento (h), el portugués lo hace en el primero; ex: isobara / isóbara,

— cuando el español mantiene la acentuación de la lengua original (i), el portugués presenta mayoritariamente procesos analógicos (j) o influencia francesa (f); ex: ex: océano / oceano caníbal / canibạl y

- cuando el español procede a través de la analogía (j), el portugués procede manteniéndose fiel al latín clásico (a), a la lengua original (i) o mediante procesos analógicos (j); ex: cónclave / conclave pelícano / pelicano.

\section{BIBLIOGRAFÍA}

An Etymological Dictionary of Modern English: http://www.etymonline.com/

(Basado en Weekley's «An Etymological Dictionary of Modern English,» Klein's «A Comprehensive Etymological Dictionary of the English Language», «Oxford English Dictionary» (second edition), «Barnhart Dictionary of Etymology», Holthausen's «Etymologisches Wörterbuch der Englischen Sprache» y Kipfer and Chapman's «Dictionary of American Slang»).

Corominas, JoAn ( I964). «Qüestions onomàstiques», Serra d'Or, VI, 5, 53-57.

Correas, Gonzalo (I625). Arte de la lengua española castellana. [Emilio Alarcos García, Madrid, CSIC, 1954] Lingüística y lenguaje.

[CDH] Corpus del Nuevo diccionario histórico $(\mathrm{CDH})$ (2013). Instituto de Investigación Rafael Lapesa de la Real Academia Española: <http://web.frl.es/CNDHE>

Diccionario manual griego-español (I989) (I7. . ed.). Barcelona, Biblograf, Vox. 
[DPD] Diccionario panhispánico de dudas. http://www.rae.es/recursos/diccionarios/dpd (Real Academia Española y Asociación de Academias de la Lengua Española). [DRAE] Diccionario de la lengua española. www.rae.es (Real Academia Española).

[GDLC] Gran Diccionari de la Llengua Catalana. http://www.diccionari.cat/ (Enciclopèdia Catalana). [Houarss] Dicionário Houaiss da língua portuguesa (200I). Rio de Janeiro: Objetiva.

Diccionario bilingüe Esencial Português-Espanhol/Español-Portugués (2010). (Dir. I. Vázquez). Barcelona, Larousse.

Lausberg, Heinrich (I98I). Linguística Românica (2. ${ }^{\text {a }}$ ed.), Lisboa, Fundação Calouste Gulbenkian. (Ed. alemana 1963).

Lleal, Coloma (2008). «Enseñanza del español y diacronía», ELUA, 22, 151-168.

Penny, Ralph (200I). Gramática histórica del español, Madrid, Ariel.

Vocabolario Etimologico della Lingua Italiana (I907 [en línea 2002]). http://www.etimo.it/

[RAE] Diccionario de Autoridades (I726-39). Real Academia Española. Madrid, Impres. Francisco del Hierro.

Teyssier, Paul (1980). História da Língua Portuguesa, Lisboa, Sá da Costa Editora. [Tradução de Celso Cunha do original francês: Histoire de la langue portugaise, Presses Universitaires de France, «Que sais-je?», 1980].

[TLFI] Le Trésor de la langue française informatisé (1971-1994). http://atilf.atilf.fr/

VÁzQuez DiéGuez, Ignacio (20I3). «El policía y o polícia: la adaptación de helenismos acabados en -ía/-ia que generan diferente pronunciación en español y portugués», Ianua. Revista Philologica Romanica, Instituto de Estudios Románicos, vol 13, n. ${ }^{\circ} 2,171-204$. 